\title{
Tumors Registry in Low Income Countries' Hospital: A Retrospective Study of 350 Cases in the Democratic Republic of Congo from 2007 to 2017
}

\author{
Mwenze Didier ${ }^{1}$, Kyabu Véronique ${ }^{1}$, Mulenga Phillipe ${ }^{2}$, Mukalay Abdon ${ }^{2}$, Ilunga Julien ${ }^{1, *}$ \\ ${ }^{1}$ Pathology Department, University of Lubumbashi, Lubumbashi, Democratic Republic of Congo \\ ${ }^{2}$ Public Health Department, University of Lubumbashi, Lubumbashi, Democratic Republic of Congo
}

Email address:

nijulien2011@yahoo.com (I. Julien)

${ }^{*}$ Corresponding author

To cite this article:

Mwenze Didier, Kyabu Véronique, Mulenga Phillipe, Mukalay Abdon, Ilunga Julien. Tumors Registry in Low Income Countries' Hospital: A Retrospective Study of 350 Cases in the Democratic Republic of Congo from 2007 to 2017. International Journal of Clinical Oncology and Cancer Research. Vol. 4, No. 2, 2019, pp. 25-28. doi: 10.11648/j.ijcocr.20190402.13

Received: April 2, 2019; Accepted: May 21, 2019; Published: June 11, 2019

\begin{abstract}
Tumors had been misdiagnosed and under- documented for longtime in Africa. The Democratic Republic of Congo (DRC) has not any cancer registry available up today. The National Cancer Registry is an important tool to deal with cancer management, especially for the National Cancer Plan and cancer prevention. The African Cancer Registry Network (AFCRN) is trying to help many Countries to hold their national Registries in hope to provide tumors' data. Despite National Cancer Registry, hospital Registries can be used for preliminary researches. This is a retrospective study performed to determine epidemiological and clinical data of tumors in Lubumbashi City, the second city in DRC, especially in the mines' hospital during the period from 2007 to 2017. The authors collected data from 350 patients aged from 2 and 94 years. The average age was $46.3 \pm 17.9$ years. There were 299 Females and 51 males; means 85.4 vs $14.6 \%$. Tumors of the female reproductive system accounted for $72.9 \%$. Diagnosis was made by echography in $59.7 \%$ of cases. Palliative care was the main treatment in $51 \%$ of cases. This study has enlightened the fact that tumors are a serious problem of health in the Democratic Republic of Congo and there are many challenges to improve cancer survival in this country.
\end{abstract}

Keywords: Tumors, Low Income Countries, Registry, Survival

\section{Introduction}

Tumors are one of the usual causes of death after cardiovascular diseases in France as in western countries [1]. In sub-Saharan zone, tumors have been under- documented [26]. Some African countries have been helped by the African Cancer Registry Network (AFCRN). Some countries like Congo-Brazzaville possesses a National Cancer Registries [4]. It is well known that the National Cancer Registry is an important tool to deal with cancer management, especially for the National Cancer Plan and cancer prevention. The Democratic Republic of Congo is also informally designated Congo-Kinshasa to distinguish it from Congo-Brazzaville (or Republic of Congo). It is a large country which area is about 2.3 million $\mathrm{km}^{2}$; this means about 33 times larger than Benelux (Belgium, the Netherlands and Luxembourg), four times more than France or twice as large as Quebec (Canada), which is the equivalent of the whole of Europe, minus Spain and the United Kingdom. The population is estimated about 80000000 inhabitants. The DRC is also a low-income country and one of the poorest countries in the world despite its geological richness. It ranks 168th on the Human Development Index [7]. The National Cancer registry is lacking. Consequently, the Democratic Republic of Congo has many cancer challenges: diagnosis and treatment of cancer are still unreachable by almost all the patients and the prognosis of cancers remains very bad despite scientific progress. The is not any National Cancer Registry.

The main of this study is to determine the clinical and the epidemiological profile of tumors in Lubumbashi, the second city of the DR Congo whose population is about 4000000 inhabitants. This will help the country to possess population- 
based cancer registry. This Cancer registry may be a Regional Registry because of its large area and later when possible a National Registry.

\section{Methods, Patients and Statistical Analysis}

This is a retrospective descriptive and transversal study. The study recorded data only from mines' hospital of Katanga, the Gecamines. Katanga is a state which area encompasses 497,000 square kilometers $(49,700,000$ ha). Its population is estimated approximately to 8.5 million. Data were collected from hospital registry in the Mines' Hospital of Lubumbashi (GECAMINES). Only patients registered for tumor from 2007 to 2017 with some were selected. All the patients without a diagnosis of tumor were excluded. The diagnosis of tumor was made clinically or by paraclinical methods. These were mainly echography and histopathology. Epidemiological, clinical and histological data examined were the age and the sex of patient, the diagnosis method of tumor (clinical or para-clinical), the tumor site, the treatment and the fate of the patient at the end of hospitalization. A total of 350 patients were selected. Data were collected on excel program and analyzed by the mean of Epi Info program, version 3.5.1. Qualitative data were represented as number (n) and percentage.

\section{Results}

\subsection{The Age of Patients}

Patients average age were $46.3 \pm 17.9$ years. The younger patient were 2 years old and the oldest 94 years. Data are reported in Figure 1. This shows that tumors are recorded in all age's groups and mostly between 40 and 60 years, that means in the active population.

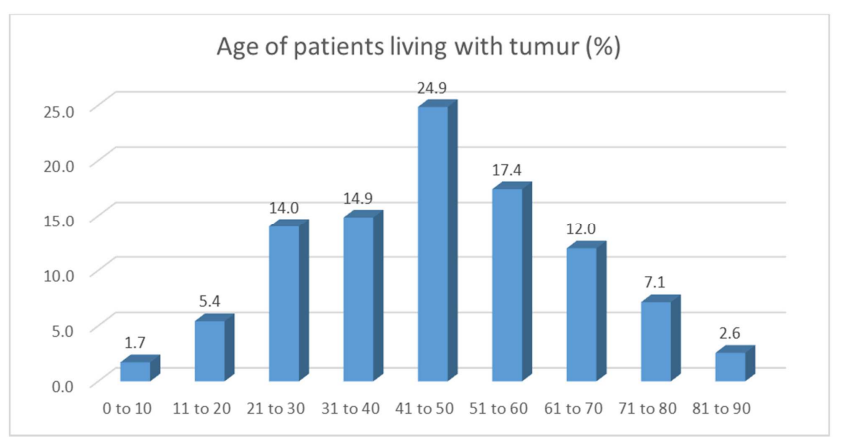

Figure 1. Age of Patients.

\subsection{The Sex of Patients}

There were 299 females $(85.4 \%)$ and 51 (14.6\%) males registered for tumor from 2007 to 2017 in the Gecamines'hospital. This study shows that Tumors seems to be recorded most in the female gender that in male patients (Figure 2) and in the male gender, they seem to be observed most after the mean age (Figure 3 ).

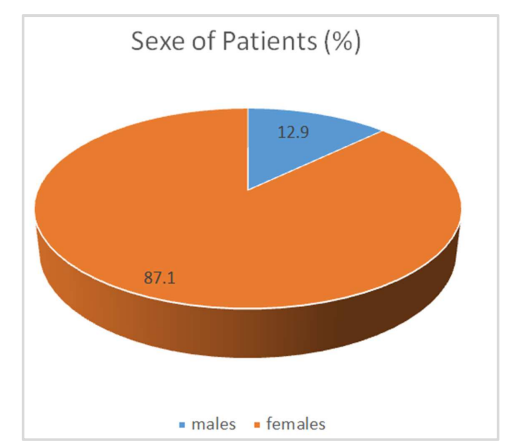

Figure 2. Sex of Patients.

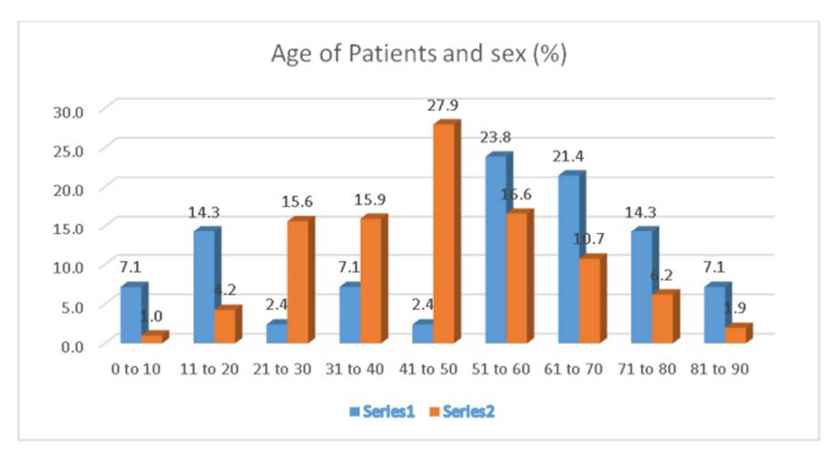

Legends: Serie 1 (males) Serie 2 (Females)

Figure 3. Age and Sex of Patients.

\subsection{The Method of Diagnosis}

Diagnosis was made clinically or by echography in $59.7 \%$. Only 22 tumors $(6.3 \%)$ were diagnosed by histopathology. Table 1 is reporting the mean of tumors' diagnosis.

Table 1. Methods of diagnosis of tumors.

\begin{tabular}{lllll}
\hline Method & Echography & Clinic & Histopathology & Total \\
\hline $\mathrm{Nb}$ & 209 & 119 & 22 & 350 \\
$\%$ & 59,7 & 34 & 6,3 & 100 \\
\hline
\end{tabular}

\subsection{The Site of Tumor}

In 255 cases of patients $(72.9 \%)$, the tumor was localized in the female genital site (Figure 4)

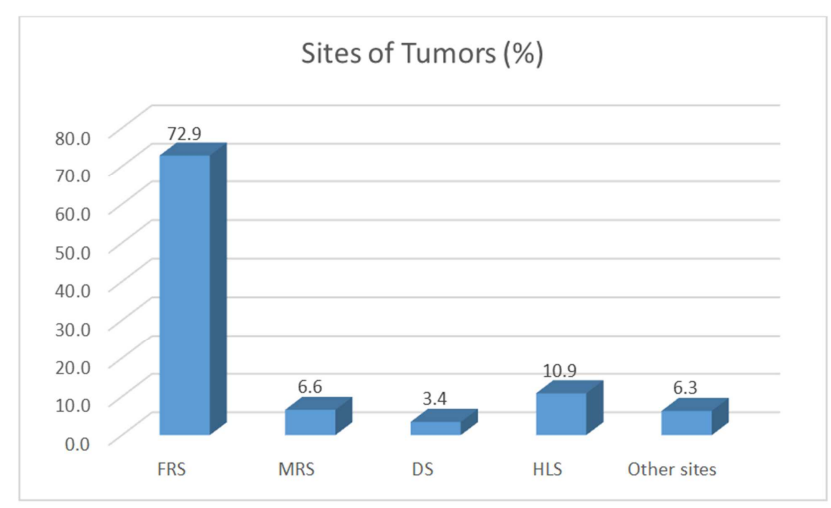

Figure 4. Sites of Tumors.

Legends:

FRS (Female Reproductive System), MRS (Male Reproductive System), DS (Digestive System), HLS (Hemato-lymphoid System) 


\subsection{The treatment of Patients Living with Tumor}

Almost half of the patients were treated by palliative care (51\%). Chemotherapy was used only in 15 patients, which means $4.3 \%$ of cases. Chemotherapy was available only in $4 \%$ of the patients registered. Many patients did not have specific treatment (Table 2).

Table 2. Methods of treatment of Patients.

\begin{tabular}{llllll}
\hline Treatment & $\begin{array}{l}\text { Non } \\
\text { Specific }\end{array}$ & Surgery & $\begin{array}{l}\text { Hormon- } \\
\text { therapy }\end{array}$ & Chemotherapy & Total \\
\hline Effectif & 179 & 137 & 20 & 15 & 350 \\
$\%$ & 51 & 39 & 5,7 & 4,3 & 100 \\
\hline
\end{tabular}

\subsection{The fate of Patients Living with Tumor}

Among the 350 patients recorded for tumor, 249 of them died during the period of study, which means $71.1 \%$ of patients (Figure 5). This may be the argument that the tumor were most malignant than benign.

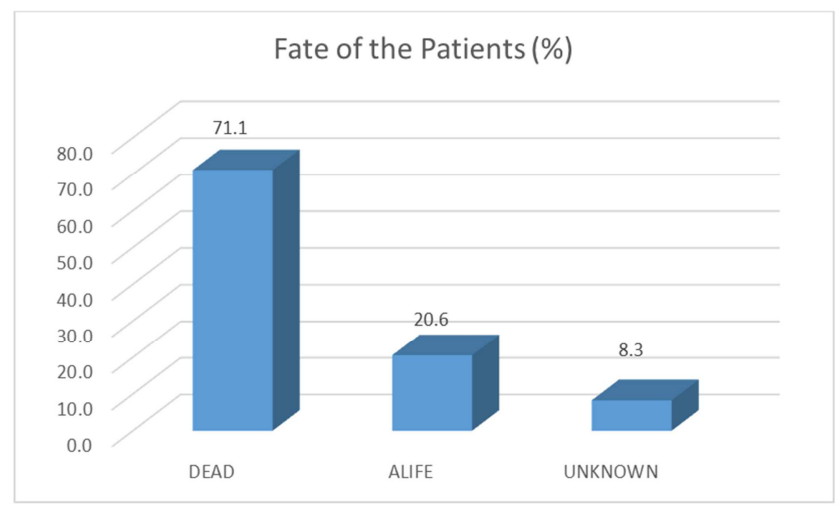

Figure 5. Fate of the Patients.

\section{Discussion}

\subsection{Age of Patients}

This study shows that tumors are recorded in all age's groups of patients. They are mostly diagnosed between the fourth and the sixth decades that means in the active population. Patients living with tumor in sub-Saharan countries as in this study are young and the average age is around 45 years. This was found by Mwenze et al and by Nday et al in the same country as in this study $[5,6]$. It was the same for Hill at. Al, Malanda et al, Giovannini et al and Mignot et al [1, 4, 8, 9]. Cancer has a burden is men life and remain a great challenge in Africa for most patients have little possibility to have specific treatment. The only way to treat cancer in Low resource's countries remains surgery. In the present study, chemotherapy has been available only for less than $10 \%$ of patients.

\subsection{Sex of Patients}

This study shows also that the female gender is mostly living with tumor. This were reported also by Malanda et al, Rigal et al and Tore et al $[4,11,12]$.

\subsection{Site of Tumor}

Tumors are also localized most in the female reproductive system in this study as in others [13-18]. To improve life quality of patients living with tumor, attention should be then directed first to women.

\subsection{The Mean of the Diagnosis}

Diagnosis is made in most case echography in 59.7\%. Only 22 tumors $(6.3 \%)$ are diagnosed by histopathology. These observations enlighten the fact that tumor diagnosis remains a big challenge in low income countries. For Pitche et al and Sano et al this observation can also be explained by the small number of pathologists or pathology laboratories in these countries $[15,16]$. In most cases, the histopathology diagnosis is performed at the latest stage of the disease. This have been documented by Nday et al in case of breast cancer [6].

\subsection{The Treatment and the Prognosis of the Patients}

In the Democratic Republic of Congo as in other African countries, cancers are mostly diagnosed at the latest stage (stage 3 or 4 ) as reported by Nday et al, Harouna et al and Karayuba et al $[6,17,18]$. Chemotherapy and radiotherapy are out of reach of most of the patients. This may be the reason why most of the patients registered passed away. Palliative care is sometimes used in low income countries when possible [8]. The prognosis of most all the patients living with tumor is aggravated by the latest diagnosis and by the lake of specific treatment. For Toure et al and Takongmo et al $[19,20]$ the treatment given to the patients in low income countries is mainly palliative. All these observations show that tumors must be considered as health public mater in the Democratic Republic of Congo and are advocacy arguments for diagnosis, prevention, and treatment of cancer in low income countries. To provide statistical data tumor registry should be one of the main challenge in the Democratic Republic of Congo. It is true that things are starting to go a little well by actions of some cancer local and international associations. The onco-pediatric franco-african group for example is helping children living with cancer since 2013 in DRC. Some data are available by the participation of many international cancer associations like the world alliance against cancer and the Congolese league against cancer. It was by these means that papers on cancer were published by Mwenze et al, Ilunga et al and Nday et al [5, 21-23]. The African Cancer Registry Network (AFCRN) has been acting since many decades in Africa. Actually, about 22 countries have a National Cancer Registry based on population in Africa [24]. There is not National Cancer Registry in the Democratic Republic of Congo. This study is a call for the Democratic Republic of Congo to start Cancer Control like other countries.

\section{Conclusion and Recommendations}

This retrospective descriptive and transversal study 
performed in the GECAMINES hospital in Lubumbashi has shown that tumors are not infrequent in the Democratic of the Congo. Patient's average age is around $46.3 \pm 17.9$ years. Tumors affect more women than men and the female reproductive system is the most site of tumor localization. Histopathology is rarely used for the diagnosis. Death is the fate observed in almost all the patients before 10 years. To improve the life of patients living with tumor, challenges include tumor diagnosis, research, prevention and treatment. These cannot be possible without National Cancer Registry.

\section{References}

[1] Hill C, Doyon F. Fréquence des cancers en France. Bull Cancer (Paris). 2003; 90(3): 207-213.

[2] Thijs A. Considérations sur les tumeurs malignes des indigénes du Congo belge et du Ruanda-Urundi. A propos de 2,536 cas. Ann Soc Belg Med Trop. 1957; 37: 483-514.

[3] Goumbri OM, Domagni OE, Sanou AM, Konsegre V, Soudre RB. Aspects épidémiologiques et histopathologiques des cancers au Burkina Faso. J Afr CancerAfrican J Cancer. 2009; 1(4): 207.

[4] Malanda JN, Mbon JBN, Bambara AT, Ibara G, Minga B, Epala BN, et al. Douze années de fonctionnement du registre des cancers de Brazzaville. Bull Cancer (Paris). 2013; 100(2): $135-139$.

[5] Mwenze Didier, Mujanay Bernard, Mukalay Abdon, Ilunga Julien. Cervical smears: morphological and epidemiological study for intra-epithelial neoplasia in Lubumbashi. International Journal of Clinical Oncology and Cancer Research 2018; 3(4): 55-58

[6] Nday G, Kabamba M, Mukalay A, Tshilombo F, Odimba E, Lebwaz B, Kalenga P, Ilunga J. Breast Cancer: Clinical and Pathological Study at Lubumbashi and Kinshasa University Hospitals in the Democratic Republic of Congo from 2014 to 2015; International Journal of Clinical Oncology and Cancer Research 2017; 2(6): 141-148

[7] Human Development Index 2007, the United Nations Development Programme 1 UN Plaza, New York, New York, 10017, USA: 283

[8] Giovannini M, Bardou VJ, Barclay R, Palazzo L, Roseau G, Helbert $T$, et al. Anal carcinoma: prognostic value of endorectal ultrasound (ERUS). Results of a prospective multicenter study. Endoscopy. 2001; 33(03): 231-236

[9] Baulieux J, Adham M, Oussoultzoglou E, De la Roche E, Berthoux N, Bourdeix $\mathrm{O}$, et al. La pancréatectomie pour cancer avec résection des vaisseaux rétropancréatiques est-elle justifiée? Chirurgie. 1998; 123(5): 438-444.

[10] Mignot L, Cottu PH. Les tumeurs desmoïdes. Oncol-PARIS-. 2002; 4(3): 163-170

[11] Rigal O, Blot E, Druesne L, Chassagne P. Épidémiologie: cancer et sujet āge. Rev Francoph Psycho-Oncol. 2006; 5(3): 141-146.
[12] Torre LA, Bray F, Siegel RL, Ferlay J, Lortet-Tieulent J, Jemal A. Global cancer statistics, 2012. CA Cancer J Clin. 2015; 65(2): 87-108.

[13] Hasiniatsy NRE, Rabarijaona L, Rafaramino F. Évolution des aspects épidémiologiques du cancer du col utérin dans le service oncologie d'Antananarivo, MadagascarEvolution of epidemiological aspects of uterine cervix cancer in Antananarivo oncology service, Madagascar. African J Cancer. 2011; 3(1): 3-7.

[14] Dem A, Traoré B, Dieng MM, Diop PS, Ouajdi T, Lalami MT, et al. Les cancers gynécologiques et mammaires à l'Institut du cancer de Dakar. Cah Détudes Rech Francoph. 2008; 18(1): $25-29$.

[15] Pitche P, Tchamdja S, Nappo-Koura G, Bakonde P, Kpodzro $\mathrm{K}$, Tchangai-Walla $\mathrm{K}$. Les cancers cutanés en consultation dermatologique à Lomé (Togo). Médecine D’Afrique Noire. 1997; 44: 15-17.

[16] Sano DI, Cisse R, Dao B, Lankoande J, Traore SSL, Soudre $\mathrm{RB}$, et al. Le cancer du sein: problèmes diagnostiques et thérapêutiques au CHU de Ouagadougou. Médecine D'Afrique Noire. 1998; 45(5).

[17] Harouna YD. La femme d'Afrique et son chirurgien face au cancer du sein. Médecine Afr Noire. 2001; 48(2).

[18] Karayuba R, Armstrong O, Bigirima V, Ndarugirire F, Ngendahayo L, Marerwageta L. Le traitement chirurgical des cancers gastriques au CHU de Kamenge (Bujumbura). A propos de 53 cas. Med D’Afrique Noire. 1993; 40: 605-608.

[19] Toure M, Nguessan E, Bambara AT, Kouassi YKK, Dia JML, Adoubi I. Facteurs liés au diagnostic tardif des cancers du sein en Afrique-sub-saharienne: cas de la Côte d'Ivoire. Gynécologie Obstétrique Fertil. 2013; 41(12): 696-700.

[20] Takongmo S, Yomi J, Guifo ML, Tangnyin CP, Ndom P, Nkodo JM, et al. Chimiothérapie néoadjuvante et cancers du sein avancés ou inflammatoires à Yaoundé (Cameroun) Neoadjuvant chemotherapy in the treatment of advanced and inflammatory breast cancer in Yaoundé (Cameroon). J Afr CancerAfrican J Cancer. 2011; 3(3): 175-179

[21] Ilunga Nikulu Julien, Lukamba Mbuli Robert, Chenge Gaby, Ngoy Numbi Marcel, Kanteng Gray, Mutoke Guélord, Kyabu Kabila and Mwenze Mwadi. Retinoblastoma: A Retrospective Study of 27Cases at the University Teaching Hospital of Lubumbashi-DRC. J Cancer Sci Clin Oncol: 3(2): 2016: 206.

[22] Ilunga J, Raphael M, Hurwitz N, Leoncini L, Githang'a J, Lebwaze B, Chumba D, Anani L. Telepathology: Role in improving laboratory techniques, diagnosis and research in low resource countries. East African Journal of Pathology 2015; 2(1): 30-33.

[23] Nday Guy, Kabamba Michel, Mukalay Abdon, Tshilombo François, Odimba Etienne, Lebwaz Bienvenu, Kalenga Prospère, Ilunga Julien. Expression of Ki-67 and Prognosis of Breast Invasive Carcinoma in Congolese Women. International Journal of Clinical Oncology and Cancer Research 2018; 3(1): 1-9

[24] Le Registres des cancers: in Les Cancers en Afrique. June 2017. Source ALIAM Contre le Cancer: Paris, France: 23. 